\title{
Axillary surgery in breast cancer: An updated historical perspective
}

\author{
Francesca Magnoni a,*, Viviana Galimberti ${ }^{a}$, Giovanni Corso ${ }^{\mathrm{a}, \mathrm{b}}$, Mattia Intra ${ }^{\mathrm{a}}$, \\ Virgilio Sacchini ${ }^{\mathrm{a}, \mathrm{b}}$, Paolo Veronesi $\mathrm{a}^{\mathrm{a}, \mathrm{b}}$ \\ a Division of Breast Cancer Surgery, IEO, European Institute of Oncology, IRCCS, Milan, Italy \\ ${ }^{\mathrm{b}}$ Faculty of Medicine, University of Milan, Milan, Italy
}

\section{A R T I C L E I N F O}

\section{Article history:}

Received 25 August 2020

Revised 28 September 2020

Accepted 28 September 2020

\section{Keywords:}

Breast cancer

Sentinel node biopsy

Axillary dissection

Acosog z0011

Neoadjuvant therapy

\begin{abstract}
A B S T R A C T
This historical surgical retrospection focuses on the temporal de-escalation axillary surgery, focusing on the unceasing efforts of researchers toward new challenges, as documented by extensive studies and trials. Axillary surgery has evolved, aiming to offer the best oncologic treatment and improve the quality of life of women. Axillary lymph-node dissection (ALND) has been replaced by sentinel lymphnode biopsy (SLNB) in women with early clinically node-negative breast cancer, providing adequate axillary nodal staging information with minimal morbidity, and becoming the standard of care in the management of breast cancer. However, this is only the beginning. Strategies in defining systemic and radiotherapeutic treatments have gradually been optimized, offering increasingly refined and targeted breast cancer treatment tools. In recent years, the paradigm of completion ALND after a positive SLNB has been questioned, and several studies have led to revolutionary changes in clinical practice. Moreover, the increasingly pivotal role played by neoadjuvant chemotherapy (NAC) has had a profound effect on the extent of axillary surgery, paving the way to a more finite "targeted" procedure in women with node-positive breast cancer who convert to negative nodes clinically after NAC. The utility of SLNB itself and its subsequent omission in women with negative nodes clinically and breast conservative surgery is also under scientific evaluation.

The changes over time in the surgical approach to breast cancer have been numerous and significant. The novel emerging perspective characterized by recent advances in biology and genetics, in dedicated axillary ultrasound imaging and chemotherapy regimens, is the present reality that points to the future of axillary node treatment in breast cancer.
\end{abstract}

(C) 2020 Elsevier Inc. All rights reserved.

\section{Today, looking back over history}

Axillary surgery is rooted historically in ancient medicine: from Galen (129-201 AD) until the 19th century, the "humoral theory," conceived by Hippocrates (460-377 BC), fed the belief that breast cancer represented a disease with systemic potential, promulgating the pivotal role of surgery in breast cancer treatment [1]. In 1757, the French physician Henri F. Le Dran was one of the first surgeons to support the concept of axillary dissection as an integral part of the surgical treatment of breast cancer [2]. In 1866, the German pathologist Rudolph Virchow, supported by robust autopsy studies, postulated that the axillary lymph nodes represented the point of spread via the lymphatics to distant sites [1,3]. Following this hypothesis, William Halsted proposed the principle that the surgical approach to breast cancer should comprise extirpation of

\footnotetext{
* Corresponding author.

E-mail address: francesca.magnoni@ieo.it (F. Magnoni).
}

the breast and adjacent lymph nodes and promoted radical mastectomy, whereby the breast, pectoralis muscles, and ipsilateral axillary nodes were removed en bloc [4,5]. In the early years of the 20th century, the anatomical extension of the Halsted technique was debunked and in order to reduce the disfigurement patients who underwent surgery experienced, gave way to modified radical mastectomy-the approach that became the gold standard of "current best practice" in breast cancer treatment until the mid1980s. Going through the first critical disquisitions in the 1970s, 2 large trials, the Kings/Cambridge and NSABP-04 trials, questioned the modified radical mastectomy axiom. They randomized patients with a clinically node-negative axilla to either early or delayed axillary treatment. And in the mid-1980s, we saw the beginning of a gradual de-escalation in axillary surgery [6].

Guided by this "diachronic" premise, in the 1990s, we reached a historical switch from axillary lymph-node dissection (ALND) to sentinel lymph-node biopsy (SLNB). SLNB became a very important scientific development for women with early-stage breast cancer and is the current best practice standard of care for most patients 
Table 1

Negative SLN.

\begin{tabular}{|c|c|c|c|}
\hline Study & Design & Results & Comments \\
\hline $\begin{array}{l}\text { NSABPB-32 } \\
\text { Krag et al [11] }\end{array}$ & $\begin{array}{l}\text { 5,611 men with invasive BC } \\
\text { randomly assigned to either: } \\
\text { - Group 1: SLN } \\
\text { resection + ALND or } \\
\text { - Group 2: SLN resection alone } \\
\text { with ALND only if SLNs were } \\
\text { positive } \\
\text { Primary endpoint = OS }\end{array}$ & $\begin{array}{l}\text { - OS: Unadjusted HR=1.20 (95\%CI 0.96-1.50; } \\
\text { p=0.12) } \\
\text { - 8-year K-M for OS } \\
\text { - Group 1=91.8\% (95\%CI 90.4-93.3) } \\
\text { - Group 2: } 90.3 \%(88.8-91.8) \\
\text { - DFS: Unadjusted HR } 1.05(95 \% \mathrm{CI} 0.90-1.22 ; \\
\text { p=0.54) } \\
\text { - 8-year KM for DFS: } \\
\text { - Group 1: } 82.4 \%(80.5-84.4) \\
\text { - Group 2: } 81.5 \%(79.6-83.4) \\
\text { - Regional-node recurrences as first events } \\
\text { - Group } 1=8 \\
\text { - Group } 2=14(\mathrm{p}=0.22)\end{array}$ & $\begin{array}{l}\text { - SLNB neither prejudiced survival nor } \\
\text { increased the risk of recurrence } \\
\text { - There were no statistically significant } \\
\text { differences between patients who } \\
\text { underwent an ALND and those who had a } \\
\text { SLNB in terms of OS, DFS and regional } \\
\text { control } \\
\text { - BC with clinically negative lymph nodes: } \\
\text { When SLN is negative, SLN alone with no } \\
\text { further ALND is appropriate, safe, and } \\
\text { effective }\end{array}$ \\
\hline $\begin{array}{l}\text { European Institute } \\
\text { of Oncology } \\
\text { Veronesi et al [12] }\end{array}$ & $\begin{array}{l}516 \text { patients with primary BC } \\
\text { up to } 2 \mathrm{~cm} \text { in pathologic } \\
\text { diameter randomized to: } \\
\text { - SLNB + ALND (ALND arm) } \\
\text { - SLNB with ALND only if the } \\
\text { sentinel node contained } \\
\text { metastases (SLN arm) }\end{array}$ & $\begin{array}{l}\text { - Eight patients in ALND arm had } \\
\text { false-negative SLNs on histologic analysis: } \\
\text { - Only } 2 \text { of } 8 \text { ( } 95 \% \text { CI: } 3-15) \text { expected cases of } \\
\text { overt axillary metastasis occurred in the } \\
\text { SLNB arm } \\
\text { - } 23 \text { breast cancer-related events in the SNB } \\
\text { arm } 26 \text { in the ALND arm (log-rank, } \\
\text { P = 0.52) } \\
\text { - OS was greater in the SLNB arm (log-rank, } \\
P=0.15)\end{array}$ & $\begin{array}{l}\text { - No differences were demonstrated in terms } \\
\text { of axillary recurrences or distant } \\
\text { metastases between patients who } \\
\text { underwent SLNB alone and patients who } \\
\text { underwent SLNB plus immediate ALND, if } \\
\text { the SLN was negative } \\
\text { - Sentinel nodes should be examined before } \\
\text { ALND. } \\
\text { - Preservation of lymph nodes may have } \\
\text { beneficial consequences }\end{array}$ \\
\hline
\end{tabular}

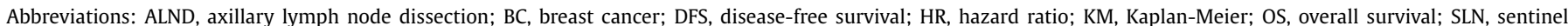
lymph node; SNB, sentinel lymph node biopsy.

with clinically negative nodes. It has revolutionized the management of the axilla and has substantially influenced the quality of care of women with a diagnosis of breast cancer.

This unique scientific evolution on the role of axillary surgery in breast cancer has developed through the study of different clinical conditions, concerning the pathologic status of sentinel lymph nodes (SLNs): negative SLN, micrometastatic (0.2-2 mm metastasis) SLN, and macrometastatic (larger than $2 \mathrm{~mm}$ metastasis) SLN [7]. These are reviewed below.

\section{Negative SLN}

In recent decades, there has been widespread acknowledgement of the role of axillary surgery as a staging and prognostic implement rather than a therapeutic intervention (Table 1) [8]. Several factors have contributed to the progressive decrease in the extent of axillary surgery. These are: the considerable expansion in screening mammography, the increasing value of adjuvant and systemic therapies and radiotherapy, the current relevance of biological markers (eg, intrinsic molecular subtypes, tumor grade, ki-67) for prognostic purposes and the personalization of adjuvant therapy, as well as the importance of neoadjuvant systemic therapy.

ALND has thus been gradually abandoned in patients whose axillary nodes are clinically negative, also because of considerable intrinsic morbidity, such as lymphedema of the arm and hand, restriction of arm mobility, and even weakness and paresthesia [9]. For patients with clinically node-negative primary breast cancer, in the 1990s, at least seven randomized trials compared SLNB versus standard ALND [6]. These trials consistently demonstrated that morbidity is lower, and quality of life is higher in patients who undergo SLNB compared to standard ALND, without adverse effects on survival in long-term follow-up [10].

The largest of these trials comparing SLNB versus standard ALND was NSABP-B32, which randomized 5,611 women between 1999 and 2004 to either an SLNB plus ALND (group 1) or SLNB alone with ALND only if the sentinel nodes were positive (group 2) [11]. This trial concluded that SLNB neither prejudiced survival nor increased the risk of recurrence. There were no statistically significant differences between patients who underwent an ALND and those who had a SLNB in terms of overall survival, diseasefree survival, and regional control [11]. Similarly, in the randomized trial conducted at the European Institute of Oncology, between 1998 and 1999, 516 patients were randomized to SLNB plus ALND versus SLNB alone (ALND again only if the sentinel lymph nodes were positive). No differences were demonstrated in terms of axillary recurrences or distant metastases between patients who underwent SLNB alone and patients who underwent SLNB plus immediate ALND, if the SLN was negative [12].

Clinical presentation of lymph nodes (negative or positive at clinical or instrumental ultrasound examination of the axilla), extent of surgical breast treatment planned (quadrantectomy or mastectomy), and scheduling of adjuvant radiotherapy, are all elements involved in the choice of axillary surgical treatment type. SLNB is a minimally invasive procedure, and is the current best standard approach to the axilla in patients with clinically node-negative breast cancer. It is universally accepted as the turning point in axillary surgery.

As science has progressed over the years, further studies have been published in the peer-reviewed biomedical literature. This criterion is applicable in mastectomy as well as in breastconserving surgery with subsequent whole breast radiation. This precise and reliable method presents axillary recurrence rates of less than $1 \%$, ensuring excellent regional nodal control, with a reported false-negative rate (FNR) of $6 \%-8 \%[10,13]$.

\section{Ductal carcinoma in situ}

This SLNB perspective also applies to breast ductal carcinoma in situ (DCIS), also defined as ductal intraepithelial neoplasia (DIN), according to the acronym introduced by Tavassoli in 1998 for DCIS (Table 2) [14]. Before the SLNB era, ALND was performed together with breast surgery in patients with DCIS [14]. ALND may nowadays appear to be unnecessary in the surgical management of DCIS since, by definition, DCIS is a noninvasive disease and thus has no potential to spread to the axillary lymph nodes [15]. But following this logic, SLNB also does not seem appropriate, and thus remains controversial [16]. A retrospective study conducted in 2008 at the European Institute of Oncology involving 854 cases of 
Table 2

Ductal carcinoma in situ.

\begin{tabular}{|c|c|c|c|}
\hline Study & Design & Results & Comments \\
\hline $\begin{array}{l}\text { European Institute of Oncology, } \\
\text { Italy } \\
\text { Intra et al [17] }\end{array}$ & $\begin{array}{l}854 \text { patients with pure } \\
\text { DCIS underwent SLN } \\
\text { biopsy at the European } \\
\text { Institute of Oncology }\end{array}$ & $\begin{array}{l}\text { - SLN metastases detected in } 12(1.4 \%) \text { of } \\
\text { DCIS pts } \\
\text { - Micrometastases }(<2 \mathrm{~mm}) \text { in } 7 \\
\text { - Macrometastases in } 5 \\
\text { - Isolated tumoral cells }(<0.2 \mathrm{~mm}) \\
\text { identified in } 4 \text { patients } \\
\text { - } 11 \text { patients underwent ALND; none } \\
\text { had additional positive axillary lymph } \\
\text { nodes }\end{array}$ & $\begin{array}{l}\text { - Routine ALND can be avoided in } \\
\text { patients with "pure" DCIS with a } \\
\text { metastatic SLN } \\
\text { - Because of the low prevalence of } \\
\text { metastatic involvement, SLN biopsy } \\
\text { should not be considered a standard } \\
\text { procedure in the treatment of all } \\
\text { patients with DCIS } \\
\text { - The sole criteria for proposing SLN } \\
\text { biopsy in DCIS should be when there } \\
\text { exists any uncertainty regarding the } \\
\text { presence of invasive foci at definitive } \\
\text { histology }\end{array}$ \\
\hline $\begin{array}{l}\text { USA National Cancer Database } \\
\text { Study } \\
\text { James et al [19] }\end{array}$ & $\begin{array}{l}\text { 15,422 patients with DCIS } \\
\text { undergoing BCS in } 2015 \\
\text { were extracted from the } \\
\text { National Cancer Data } \\
\text { Base }\end{array}$ & $\begin{array}{l}\text { - } 18 \% \text { rate of use of SLNB and a very low } \\
\text { rate of positive SLN }(0.9 \%) \\
\text { - Significant association between } \\
\text { frequency of SLNB and } \\
\text { - Patients } 60-69 \text { years old } \\
\text { - Receipt of care at a community } \\
\text { facility } \\
\text { - Higher nuclear grade DCIS }\end{array}$ & $\begin{array}{l}\text { - In this large dataset of patients with } \\
\text { DCIS, SLN metastasis is rarely } \\
\text { identified. } \\
\text { - Benefit of SLNB in patients with DCIS } \\
\text { undergoing BCS is limited and does not } \\
\text { routinely provide meaningful } \\
\text { information. }\end{array}$ \\
\hline $\begin{array}{l}\text { Department of Breast Surgery, } \\
\text { Rigshospitalet (University } \\
\text { Hospital of Copenhagen, } \\
\text { Denmark) and Herlev-Gentofte } \\
\text { Hospital (Copenhagen, Denmark). } \\
\text { Munck et al [20] }\end{array}$ & $\begin{array}{l}\text { Registry-based study of } \\
1,368 \text { patients with DCIS } \\
\text { treated between } 2008 \\
\text { and } 2016 \text { evaluated; } 975 \\
\text { included in study }\end{array}$ & $\begin{array}{l}\text { - } 246 / 975 \text { ( } 25.2 \%) \text { tumors upstaged to IC } \\
\text { - Redundant SLNB performed in 392/975 } \\
\text { ( } 40.2 \%) \text {. } \\
\text { - } 44 / 975 \text { (4.5\%) with final diagnosis of IC } \\
\text { not offered SLNB and thus potentially } \\
\text { undertreated. } \\
\text { - In adjusted analysis, risk of upstaging. } \\
\text { increased with } \\
\text { - Larger DCIS size } \\
\text { - Palpability } \\
\text { - Mass formation on breast imaging } \\
\text { - Van Nuys classification not associated } \\
\text { with upstaging }\end{array}$ & $\begin{array}{l}\text { - Considerable number of patients with } \\
\text { DCIS had a redundant SLNB } \\
\text { - Utility in identification of subgroups in } \\
\text { whom SLNB can safely be omitted }\end{array}$ \\
\hline
\end{tabular}

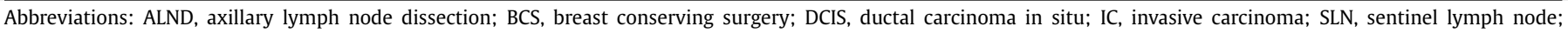
SLNB, sentinel lymph node biopsy.

pure DCIS (no microinvasive foci identified on definitive pathologic examination) found a $1.9 \%$ rate of SLN involvement. This SLN involvement rate decreased to $1.4 \%$ if SLNs with only isolated tumor cells were excluded. According to previous studies, the SLN was found to be the only metastatic node in all patients who received axillary dissection. These results suggested that routine axillary dissection could be avoided in patients with "pure" DCIS with a metastatic SLN [17].

The current clinical practice recommendation is to perform SLNB only in selected patients with DCIS in whom there is a substantial risk of an upgrade of the lesion at final pathology. A substantial risk of an upgrade includes a mass highly suggestive of invasive cancer on breast imaging and physical examination, or a wide area of DCIS of $5 \mathrm{~cm}$ or more at imaging, or when mastectomy is indicated, as confirmed by the 2014 ASCO update recommendations [18]. However, evidence for this recommendation is not strong due to the shortage of scientific data and long-term follow-up studies.

To date, a recent American contribution on this topic, in which data on 15,422 patients with DCIS undergoing BCS in 2015 were extracted from the National Cancer Data Base, revealed an 18\% rate of use of SLNB and a very low, $0.9 \%$ rate of metastatic SLN [19]. This low rate of nodal involvement argues against the routine use of SLNB for patients with DCIS undergoing BCS. Additionally, a recent register-based study conducted by Munch et al. involving 975 patients with a preoperative diagnosis of DCIS who had undergone both mastectomy and BCS reported a $25.2 \%$ rate $(246 / 975)$ of upstaged invasive cancer based on final pathology. SLNB was performed in 594/975 (60.9\%) patients-392 (53.8\%) of the 729 pa- tients with a final diagnosis of DCIS and $202(82.1 \%)$ of the 246 patients with disease upstaged to invasive cancer $(P<.001)$. Therefore, $40.2 \%$ (392/975) of patients with only DCIS confirmed at final pathology of the breast specimen had a redundant SLNB, and $44 / 975$ (4.5\%) had inadequate staging of the axilla-the 44 whose disease was upstaged to invasive cancer but did not undergo SNLB. They suggested the specific identification of "upstaging risk" subgroups in whom SLNB can safely be avoided, such as DCIS lesion size, palpability or mammographic mass, nuclear grade, and presence of comedo-necrosis, even though in the present study they were combined in the Van Nuys classification [20].

\section{Micrometastatic SLN}

Two trials have studied the surgical management of microscopic SLN disease in recent decades (Table 3). The phase 3 International Breast Cancer Study Group (IBCSG) 23-01 multicenter, randomized, noninferiority trial was conducted at the European Institute of Oncology. It underlined that axillary dissection provides no advantage in patients who undergo conservative surgery or mastectomy with only micrometastases in the SLN (1 or more foci up to $2 \mathrm{~mm}$ ). After a median follow-up of 9.7 years (interquartile range 7.8-12.7), the authors could not find any difference in disease-free survival, overall survival, or recurrence $[21,22]$. Similar conclusions were reported in AATRM 048/13, which randomized patients with invasive breast cancer with tumor sizes $<3.5 \mathrm{~cm}$ and micrometastatic lymph node disease to either no further surgery or ALND, after BCS and SLNB. The investigators concluded that axillary dissection is not justified in patients with limited SLN 
Table 3

Micrometastatic SLN.

\begin{tabular}{|c|c|c|c|}
\hline Study & Design & Results & Comments \\
\hline $\begin{array}{l}\text { IBCSG 23-01 } \\
\text { Galimberti et al }[21,22]\end{array}$ & $\begin{array}{l}\text { - Randomized, non-inferiority, phase } 3 \\
\text { trial } \\
\text { - Eligible patients: } \\
\text { - Clinically non-palpable axillary } \\
\text { lymph node(s) } \\
\text { - Primary tumor } \leq 5 \mathrm{~cm} \\
\text { - } \geq 1 \text { micrometastatic ( } \leq 2 \mathrm{~mm} \text { ) SLN } \\
\text { with no extracapsular extension } \\
\text { SNB } \\
\text { - Patients randomly assigned } 1: 1 \text { ratio to } \\
\text { undergo ALND or no ALND }\end{array}$ & 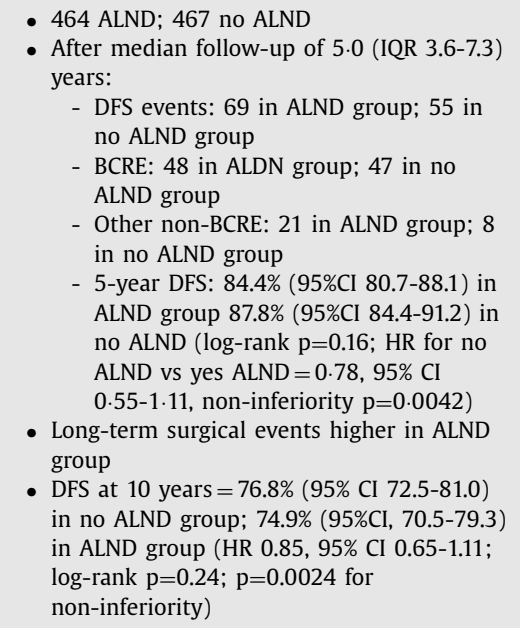 & $\begin{array}{l}\text { ALND can be avoided in early BC } \\
\text { with limited SLN involvement, } \\
\text { eliminating complications of } \\
\text { ALND with no impact on } \\
\text { survival. }\end{array}$ \\
\hline $\begin{array}{l}\text { AATRM 048/13/2000 } \\
\text { Solá et al [23] }\end{array}$ & $\begin{array}{l}\text { - Prospective, randomized clinical trial } \\
\text { - Newly diagnosed early-stage breast } \\
\text { cancer ( } \mathrm{T}<3.5 \mathrm{~cm} \text {, clinical N0, M0) } \\
\text { who underwent surgical excision as } \\
\text { primary treatment } \\
\text { - All } 247 \text { patients had micrometastatic } \\
\text { SLN } \\
\text { - Randomly assigned to complete ALND } \\
\text { or clinical follow-up } \\
\text { - } 1^{\text {ry }} \text { end point = DFS }\end{array}$ & $\begin{array}{l}\text { - } 112 \text { in ALND group; } 121 \text { clinical follow up } \\
15(13 \%) \text { ALND group completion ALND } \\
\text { was positive, with a low tumor burden. } \\
\text { - Disease recurrence: } 1(1 \%) \text { of ALND group } \\
\text { and } 3(2.5 \%) \text { of clinical observation } \\
\text { - No differences in DFS ( } \mathrm{p}=0.325) \text { and no } \\
\text { cancer-related deaths }\end{array}$ & $\begin{array}{l}\text { - In early BC patients with SLN } \\
\text { micrometastasis, selective SLN } \\
\text { lymphadenectomy IS sufficient to } \\
\text { control locoregional and distant } \\
\text { disease, with no significant } \\
\text { effects on OS }\end{array}$ \\
\hline
\end{tabular}

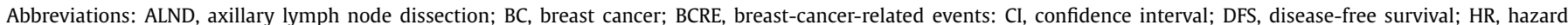
ratio; OS, overall survival; SLN, sentinel lymph node.

involvement, provided that patients receive both traditional whole breast radiation in BCS and systemic adjuvant treatment [23]. These large trials demonstrated that axillary lymph node dissection is not justified for patients with micrometastatic sentinel-node involvement and that this does not impact on survival.

\section{Macrometastatic SLN}

Biomolecular tumor pattern and SLN status alone might provide sufficient information to guide adjuvant treatment decision-making (Table 4). In addition, a low burden of residual axillary disease could potentially be eradicated with adjuvant systemic therapy or radiotherapy. In keeping with these assumptions, research efforts have attempted to answer the question of whether ALND can be avoided in specific selected presentations with limited metastatic lymph-node involvement.

The American College of Surgeons Oncology Group Z0011 clinical trial (ACOSOG Z0011) randomized women with breast cancer, and limited metastatic lymph node involvement eligible for BCS, to assess the efficacy and safety in terms of survival of performing only SLNB followed by subsequent radiation therapy. After a 10year follow-up, it emerged that ALND did not confer an advantage in women with early breast cancer treated with BCS with no more than two involved SLNs, provided they received standard whole breast irradiation and adjuvant chemotherapy. The trial revealed no significant difference in axillary recurrence rates between the observation group (1.5\%) and the ALND group $(0.5 \%)(P=.28)$ with distant disease-free survival rates of $80.2 \%$ and $78.2 \%$, respectively $(P=.32)$ [24]. In line with the ACOSOG Z0011 trial results, the current surgical conduct in BCS sees ALND as contraindicated in women with cT1-T2 breast cancer and metastases in only 1 or 2 SLNs. ALND is still recommended if there a metastasis in $\geq 3$ SLNs or macroscopic lymph node is detected intraoperatively $[8,25]$. Moreover, another large randomized European study, the phase 3 AMAROS trial (After Mapping of the Axilla: Radiotherapy Or Surgery), analyzed 1,425 women with T1-2 breast cancer, clinically negative axilla, and at least one metastatic sentinel node, comparing axillary dissection with axillary radiotherapy. After a median follow-up of 6.1 years (interquartile range 4.1-8.0), both axillary dissection and axillary radiotherapy provided similar axillary control. Moreover, radiotherapy was associated with significantly lower morbidity, with a lower risk of lymphedema [26].

These considerations do not indicate that axillary radiotherapy is always indicated in cases of positivity in the sentinel node, given the good results in outcome reported by the ACOSOG Z0011 trial, even in the absence of further axillary treatment [25]. Indeed, in the management of patients with node-positive breast cancer, the role of nodal irradiation is a matter of debate, in particular in ACOSOG Z0011 [24]. Recently, Morrow et al. specified selective high-risk clinical subgroups with 1-2 positive SLNs in which node radiotherapy is strongly recommended: (1) tumor $\geq 3 \mathrm{~cm}$; (2) tumor with lymphovascular invasion; (3) microscopic extracapsular extension of metastases in SLNs [27].

The monocentric OTOASOR trial (Optimal Treatment of the Axilla-Surgery Or Radiotherapy) confirmed the AMAROS findings. Among 2,073 patients with early breast cancer and low SLNB burden, axillary nodal irradiation was noninferior to completion ALND in terms of survival and regional recurrence [28].

At the European Institute of Oncology, a retrospective study of 1,386 consecutive women with a diagnosis of cT1-2N0 breast cancer who underwent BCS between 2016 and 2018, analyzed SLNB status and related surgical management: $1,156(83.4 \%)$ patients resulted negative and 230 positive (16.6\%). Seven of these 230 patients (3.0\%) underwent complete ALND, and 223 (97.0\%) were ob- 
Table 4

Macrometastatic SLN.

\begin{tabular}{|c|c|c|c|}
\hline Study & Design & Results & Comments \\
\hline $\begin{array}{l}\text { ACOSOG Z0011 trial } \\
\text { Giuliano et al [24] }\end{array}$ & $\begin{array}{l}\text { - Determine if outcomes of patients with } \\
\text { SLN metastases treated with BCS and } \\
\text { SLNB alone without ALND is } \\
\text { noninferior to that of women treated } \\
\text { with ALND } \\
\text { - } 446 \text { in SLNB alone group and } 445 \text { in } \\
\text { ALND group }\end{array}$ & $\begin{array}{l}\text { - At median follow-up of } 9.3 \text { years } \\
\text { (interquartile range, } 6.93-10.34 \text { years) } \\
\text { - } 10 \text {-year OS } 86.3 \% \text { in the SLNB } \\
\text { alone group and } 83.6 \% \text { in the ALND } \\
\text { group (HR, } 0.85 \text { [1-sided } 95 \% C I \text {, } \\
0-1.16 \text { ]; noninferiority } \mathrm{P}=.02 \text { ). } \\
\text { - } 10 \text {-year DFS } 80.2 \% \text { in the SLNB } \\
\text { alone group and } 78.2 \% \text { in the } \\
\text { ALND group (HR, } 0.85 \text { [95\% CI, } \\
\text { 0.62- } 1.17] \text {; } \mathrm{P}=.32 \text { ) } \\
\text { - } 10 \text {-year regional recurrence did not } \\
\text { differ significantly between the } 2 \\
\text { groups }\end{array}$ & $\begin{array}{l}\text { - Findings do not support routine use of } \\
\text { ALND in women with T1/T2 PIBC, no } \\
\text { palpable axillary adenopathy, and } 1 \text { or } \\
2 \text { sentinel lymph nodes containing } \\
\text { metastases } \\
\text { - In this patient population, based on } \\
10 \text {-year outcomes findings, ALND did } \\
\text { not confer an advantage, provided } \\
\text { women received standard whole breast } \\
\text { irradiation and adjuvant chemotherapy. }\end{array}$ \\
\hline $\begin{array}{l}\text { EORTC 10981-22023 } \\
\text { AMAROS trial (After } \\
\text { Mapping of the } \\
\text { Axilla: Radiotherapy } \\
\text { Or Surgery) } \\
\text { Donker et al [26] }\end{array}$ & $\begin{array}{l}\text { - Randomly assigned } 1425 \text { women with } \\
\text { T1-2 PBC, no palpable } \\
\text { lymphadenopathy and a positive SLN } \\
\text { to receive either ALND ( } 744 \text { ) or axillary } \\
\text { RT ( } 681 \text { ) } \\
\text { - Primary endpoint = non-inferiority of } \\
\text { 5-year axillary recurrence, considered } \\
\text { to be not more than } 4 \% \text { for the axillary } \\
\text { RT group compared with an expected } \\
2 \% \text { in the axillary lymph node } \\
\text { dissection group }\end{array}$ & $\begin{array}{l}\text { Median follow-up } 6.1 \text { years (IQR } 4.1-8.0 \text { ) } \\
\text { - } 220 / 672 \text { (33\%) who underwent ALND } \\
\text { had additional positive nodes } \\
\text { - Axillary recurrence in } 4 / 744 \text { in the } \\
\text { ALND group and } 7 / 681 \text { in the axillary } \\
\text { RT group } \\
\text { - } 5 \text {-year axillary recurrence } 0.43 \% \text { (95\% } \\
\text { CI 0.00-0.92) after ALND versus } 1.19 \% \\
\text { (0.31-2.08) after axillary RT } \\
\text { - The planned non-inferiority test was } \\
\text { underpowered because of the low } \\
\text { number of events } \\
\text { - Lymphedema in the ipsilateral arm } \\
\text { noted significantly more often after } \\
\text { ALND than after axillary RT at } 1 \text { year, } 3 \\
\text { years, and } 5 \text { years }\end{array}$ & $\begin{array}{l}\text { - ALND and axillary RT after a positive } \\
\text { SLN provide excellent and comparable } \\
\text { axillary control for patients with T1-2 } \\
\text { PBC, no palpable lymphadenopathy } \\
\text { - Axillary radiotherapy results in } \\
\text { significantly less morbidity }\end{array}$ \\
\hline $\begin{array}{l}\text { OTOASOR trial (Optimal } \\
\text { Treatment Of the } \\
\text { Axilla - Surgery Or } \\
\text { Radiotherapy) } \\
\text { Sávolt et al [28] }\end{array}$ & $\begin{array}{l}\text { - Compare cALND to RNI in patients } \\
\text { with SLN metastasis (pN1sn) in stage I } \\
\text { e II breast cancer } \\
\text { - Randomized women with PIBC (cN0 } \\
\text { and cT } \leq 3 \mathrm{~cm} \text { ) before surgery to } \\
\text { cALND (1054) or } 50 \text { Gy RNI (1052) } \\
\text { - Primary endpoint was axillary } \\
\text { recurrence and secondary endpoints } \\
\text { were OS and DFS. }\end{array}$ & $\begin{array}{l}\text { - Mean follow-up was } 97 \text { months } \\
\text { (Q1-Q3: } 80-120) \text {. } \\
\text { - Axillary recurrence } 2.0 \% \text { in cALND } \\
\text { group vs. } 1.7 \% \text { in RNI group }(\mathrm{p}=1.00) \\
\text { - OS at } 8 \text { years } 77.9 \% \text { vs. } 84.8 \% \\
\text { ( } \mathrm{p}=0.060 \text { ) } \\
\text { - DFS at } 8 \text { years } 72.1 \% \text { with cALND and } \\
77.4 \% \text { after RNI }(\mathrm{p}=0.51)\end{array}$ & $\begin{array}{l}\text { RNI without cALND does not increase } \\
\text { the risk of axillary failure in patients } \\
\text { with early-stage PIBC (cT } \leq 3 \mathrm{~cm}, \mathrm{cN} 0) \\
\text { and pN1sn } \\
\text { - In patients with limited SLN metastasis } \\
\text { axillary RNI could be an alternative } \\
\text { treatment for selected patients. }\end{array}$ \\
\hline $\begin{array}{l}\text { European Institute of } \\
\text { Oncology } \\
\text { Retrospective Study } \\
\text { Morigi et al [29] }\end{array}$ & $\begin{array}{l}\text { - Retrospective study of } 1,386 \text { women } \\
\text { with diagnosis of cT1-2N0 BC who } \\
\text { underwent BCS and SLNB between } \\
2016 \text { and } 2018\end{array}$ & $\begin{array}{l}\text { - Analyzed nodal status and related } \\
\text { surgical management: of the } 1386 \\
\text { patients who underwent surgery after } \\
\text { the introduction of the Z011 trial, } \\
7 / 230(3.0 \%) \text { with positive SLN } \\
\text { underwent complete ALND, and } \\
223 / 230(97.0 \%) \text { were observed. This } \\
\text { compares to } 1425 \text { with same } \\
\text { characteristics, treated before } \\
\text { adaptation of the Z0011 trial criteria in } \\
\text { which } 216 / 1425(15 \%) \text { underwent } \\
\text { ALND. }\end{array}$ & $\begin{array}{l}\text { - Statistically significant reduction in ALND } \\
\text { performed with decrement in consequent } \\
\text { post-operative ALND related morbidity }\end{array}$ \\
\hline
\end{tabular}

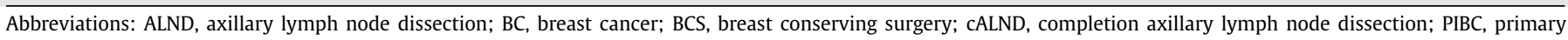
invasive breast cancer; PBC, primary breast cancer; RNI, regional nodal irradiation; RT, radiotherapy; SLN, sentinel lymph node; SLNB, sentinel lymph node biopsy.

served. This cohort was compared to 1,425 patients with the same characteristics, treated before the adaptation of the Z0011 trial criteria. In the latter, 216 (15\%) underwent ALND, demonstrating a statistically significant reduction in ALND performed following adaptation of the Z0011 trial criteria and suggesting a decrement in consequent postoperative ALND-related morbidity [29].

\section{Neoajuvant chemotherapy}

As already underlined, the role of systemic therapy with neoadjuvant intent is increasing (Table 5). Neoadjuvant chemotherapy (NAC) represents a valid tool in downstaging both breast and axillary disease. The 2019 St. Gallen Conference Panel considered SLNB appropriate in the clinically negative axilla before neoadjuvant treatments, and strongly recommended it [30]. For patients with clinically involved axillary lymph nodes, downstaged after neoadjuvant treatment, the performance of SLNB after NAC remains controversial and widely discussed in several trials. Note that a pathological complete response in node-positive cases is reported in about $40 \%$ of patients, and in $60 \%-70 \%$ of women with human epidermal growth factor receptor 2 (HER2)-positive tumors $[31,32]$. One of the main concerns remains the risk of a FNR of SLNB post-NAC, which, as reported "may range from $10 \%$ to $30 \%$," and this was considered unacceptably high [31].

Several prospective trials have investigated the risk of a FNR of SLNB post-NAC. These trials include the 3-arm NSABP B27 trial, the multicenter 4-arm SENTINA trial, the ACOSOG Z1071 trial, and the Canadian SN FNAC study analyzed FNR in cN1-N2 downstaged cN0 after NAC patients. These studies reported FNR of 10.7\%, 14.2\%, $12.6 \%$, and $8.4 \%$, respectively, with lower rates if more than 3 SLNs 
Table 5

Neoadjuvant chemotherapy.

\begin{tabular}{|c|c|c|c|}
\hline Study & Design & Results & Comments \\
\hline $\begin{array}{l}\text { European Institute } \\
\text { of Oncology, Italy } \\
\text { Galimberti et al } \\
\text { [35] }\end{array}$ & $\begin{array}{l}\text { Retrospective study of } 396 \text { cT1-4, } \\
\text { cN0/1/2 patients, who became or } \\
\text { remained cN0 after NAC and } \\
\text { underwent SLNB if at least one SLN } \\
\text { was found. ALND was not performed if } \\
\text { the SLN was negative. }\end{array}$ & $\begin{array}{l}\text { - After a median follow-up of } 61 \text { months, } \\
\text { the five-year overall survival was } 90.7 \% \\
(95 \% \mathrm{CI}, 87.7-93.7) \text { in the whole cohort, } \\
93.3 \%(95 \% \mathrm{CI}, 90.0-96.6) \text { in those initially } \\
\mathrm{cN} 0 \text {, and } 86.3 \%(95 \% \mathrm{CI}, 80.6-92.1) \text { in those } \\
\text { patients who were initially cN1/2 } \\
(\mathrm{P}=0.12) \text {. } \\
\text { - Axillary failure occurred in only } 1(0.7 \%) \\
\text { initially cN1/2 patient who became cN0. }\end{array}$ & $\begin{array}{l}\text { - Results suggested that SLNB is } \\
\text { acceptable in cN1/2 patients } \\
\text { down-staged to cN0 after NAC }\end{array}$ \\
\hline $\begin{array}{l}\text { European Institute } \\
\text { of Oncology, Italy } \\
\text { Corso et al [36] }\end{array}$ & $\begin{array}{l}444 \text { women, median age } 44 \text { years with } \\
\text { primary LABC candidates for NAC and } \\
\text { for lymphoscintigraphy before surgery }\end{array}$ & $\begin{array}{l}\text { - At least one SLN identified during } \\
\text { lymphoscintigraphy in } 96.9 \%(430 / 444) \\
\text { (95\%CI, 94.8-98.1\%). } \\
\text { - Detection rate did not vary significantly } \\
(p=0.53) \text { according to the type of NAC }\end{array}$ & $\begin{array}{l}\text { - Lymphoscintigraphy for SLN } \\
\text { identification is a feasible and safe } \\
\text { procedure post-NAC, independently } \\
\text { of treatment types. }\end{array}$ \\
\hline $\begin{array}{l}\text { GANEA2 } \\
\text { Classe et al [37] }\end{array}$ & $\begin{array}{l}\text { - Enrolled } 957 \text { women with a diagnosis } \\
\text { of early BC post-NAC } \\
\text { - Before NAC, women with cytologically } \\
\text { proven node involvement were } \\
\text { allocated into the pN1 group; others } \\
\text { into the cN0 group } \\
\text { - After NAC, pN1 group underwent SLN } \\
\text { and ALND; cN0 group underwent SLN } \\
\text { and ALND only in case of mapping } \\
\text { failure or SLN involvement. } \\
\text { - The main endpoint was SLN FNR. } \\
\text { Secondary endpoints were predictive } \\
\text { factors for remaining positive ALND } \\
\text { and OS of patients treated with SLN } \\
\text { alone }\end{array}$ & $\begin{array}{l}\text { - Observed } 103 \text { negative SLNB among } \\
\text { women in the pN1 group } \\
\text { - FNR } 11.9 \% \text { ( } 95 \% \text { CI } 7.3-17.9 \% \text { ) } \\
419 \text { patients from cN0 group treated with } \\
\text { SLNB alone, with only one axillary relapse } \\
\text { during the follow-up. } \\
\text { - Among pN1 group ( } 538 \text { ), with successful } \\
\text { mapping, } 103 \text { had a negative SLNB. The } \\
\text { FNR was } 11.9 \% \text { (95\%CI 7.3-17.9\%) } \\
\text { - In multivariate analysis residual breast } \\
\text { tumor size after NAC } \geq 5 \text { mm and } \\
\text { lympho-vascular invasion independent } \\
\text { predictors for involved ALND. } \\
\text { - Positive ALND rate of } 3.7 \% \text { in patients with } \\
\text { initially involved node, with (1) negative } \\
\text { SLNB after NAC; (2) no lympho-vascular } \\
\text { invasion; and (3) a remaining tumor size } \\
\geq 5 \text { mm - with risk regardless the number } \\
\text { of SLN removed }\end{array}$ & $\begin{array}{l}\text { - A negative SLN after NAC allows } \\
\text { surgeon to abstain from an ALND } \\
\text { - Residual breast tumor and } \\
\text { lympho-vascular invasion after NAC } \\
\text { would allow selecting patients } \\
\text { with initially involved node with a } \\
\text { low risk of ALND involvement. }\end{array}$ \\
\hline $\begin{array}{l}\text { Netherlands Cancer } \\
\text { Registry cohort } \\
\text { study } \\
\text { Simons et al [38] }\end{array}$ & $\begin{array}{l}\text { - } 12,461 \text { women with cT1-4 N0-3 BCs } \\
\text { treated with NAC - } 5830 \text { (46.8\%) cN0 } \\
6631(53.2 \%) \mathrm{cN}+ \\
\text { - Patients classified by clinical node } \\
\text { status (cN) and type of axillary surgery } \\
\text { - Analyses performed to determine } \\
\text { clinicopathological factors associated } \\
\text { with performing ALND in cN+ patients }\end{array}$ & $\begin{array}{l}\text { - SLNB only not followed by ALND in cN0 } \\
\text { patients increased from } 11 \% \text { in } 2006 \text { to } \\
94 \% \text { in } 2016 \text { ( } p<0.001) \text {. SLNB performed } \\
\text { post-NST increased from } 33 \text { to } 62 \% \text { ( } \mathrm{p}< \\
0.001 \text { ). } \\
\text { - ALND in cN+ patients decreased from } 99 \% \\
\text { in } 2006 \text { to } 53 \% \text { in } 2016 \text { ( }<<0.001 \text { ). } \\
\text { - Age, year of diagnosis, HER2-positive } \\
\text { disease, clinical tumor stage and clinical } \\
\text { nodal stage were correlated with } \\
\text { performing ALND in } \mathrm{cN}+\text { patients }\end{array}$ & $\begin{array}{l}\text { - Axillary surgical staging changed } \\
\text { significantly with a major decrease } \\
\text { in ALND rates in breast cancer } \\
\text { patients treated with NST over the } \\
\text { past decade. } \\
\text { - ALND has increasingly been } \\
\text { omitted after NAC in clinically } \\
\text { node-positive patients }\end{array}$ \\
\hline
\end{tabular}

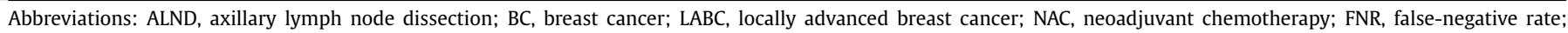
PIBC, primary invasive breast cancer; PBC, primary breast cancer; SLN, sentinel lymph node; SLNB, sentinel lymph node biopsy; NST neoadjuvant systemic therapy.

are sampled (10\% in ACOSOG Z1071), or if both radiotracer and dye are used [33]. In a recent meta-analysis, the importance of the amount of SLNs removed in terms of reducing the FNR rate is specifically highlighted. Examining a total of 1,921 women enrolled in 13 studies with initial metastatic biopsy-ascertained nodes after NAC, the meta-analysis found that the FNR rate progressively decreased from $20 \%(13-27)$ to $12 \%(5-19)$ and $4 \%(0-9)$ with removal of 1,2 , and 3 or more nodes, respectively [34].

The European Institute of Oncology conducted a retrospective study of 396 cT1-4, cN0/1/2 patients, who became or remained cNO after neoadjuvant treatment and underwent SNB if at least 1 SLN was found. ALND was not performed if the SLN was negative. After a median follow-up of 61 months, the 5-year overall survival was $90.7 \%$ (95\% confidence interval [CI], 87.7-93.7) in the whole cohort, $93.3 \%(95 \% \mathrm{CI}, 90.0-96.6)$ in those initially cN0, and $86.3 \%(95 \% \mathrm{CI}, 80.6-92.1)$ in those patients who were initially cN1/2 $(P=.12)$. Axillary failure occurred in only $1(0.7 \%)$ initially cN1/2 patient who became cN0. These results suggested that SLNB is acceptable in cN1/2 patients downstaged to cN0 after neoadjuvant therapy [35]. Moreover, Corso et al. recently described pre- operative lymphoscintigraphy is a feasible and safe procedure in SLN identification post-NAC, with an SLN detection rate of 96.9\% [36]. More recently, the GANEA2 study enrolled 957 post-NAC patients and observed 103 negative SLN among women in the pN1 group. The FNR was $11.9 \%$ (95\% CI 7.3\%-17.9\%), leading to the conclusion that a negative SLN after NAC allows the surgeon to abstain safely from an ALND [37]. To date, a recent large Dutch populationbased cohort study on 15,725 women with a diagnosis of breast cancer treated with NAC confirmed the important change in axillary surgery in clinical practice over the past decade in CT1-4 N03 breast cancers treated with NAC, demonstrating that ALND has increasingly been omitted after NAC in clinically node-positive patients [38].

To reduce the FNR, the metastatic nodes could be clipped, identified by ultrasound-guided wire localization or by a radioactive seed and removed during the SLNB procedure, in case of complete axillary response [39]. In particular, several ongoing worldwide trials are still evaluating the methodology for clipped node excision during SLNB after NAT $[32,40]$. A recent prospective trial on 98 women with cT1-4 cN1-3 breast cancer who underwent 
NAC, studied the feasibility and accuracy in excision of specific selected clipped metastatic biopsy-proven nodes: the reported SLN identification rate was $87.8 \%$. The FNR observed in $\mathrm{cN} 1$ patients was $4.2 \%$ when the clipped node was recognized as SLN, increasing to $16.7 \%$ if the removed clipped node did not correspond to the SLN. It concluded the validity of omission of ALND in patients whose nodes are clinically positive patients before NAC, become subsequently negative, if the negative clipped node is identified as SLN [41].

The 2019 St. Gallen consensus conference believed SLNB, as opposed to ALND, to be adequate if at least 3 or more negative sentinel nodes were detected and examined, underlining the persistence of high FNR unless 3 or more SNs are examined. The Panel recommended that patients with a clinically positive axilla or with macrometastases identified in SLN after NAC undergo ALND. The Panel was divided over whether residual micrometastatic lymph node involvement warranted completion dissection after NAC, concluding to be in favor of the execution of the ALND, unless regional nodal irradiation is foreseen [30].

\section{“Observing” axillary lymph nodes}

Today, the focus is increasingly shifting toward the significant role played by the tumor's biologic profile, strictly implicated not only in breast cancer diagnostic staging, but also in the personalization of its treatment, as evidenced by the eighth edition of the AJCC-TNM staging system [42]. Moreover, the SLNB-positive rate is falling below 20\%, as reported in specialized European breast centers, an encouraging result when compared to the $29 \%$ reported in the NSABP B-32 trial [43]. Additionally, a Memorial Sloan Kettering study reported a SLN-positive rate of $17.6 \%$ in a population of patients undergoing biopsy [44] while a Mayo Clinic single center analysis of 1,140 patients (T1/T2) with preoperatively confirmed clinically negative axillary nodes, reported a SLN-positive rate of $13 \%[45]$.

The clinical information offered by the lymph-node pathologic status appears mainly of prognostic value. Information regarding node status is useful in several clinical conditions, such as in the $\geq \mathrm{pN} 2$ stage, in relation to recommendations for regional radiotherapy and choice of the type and duration of systemic treatment [43]. Nevertheless, specific biological and genetic parameters are primarily implicated in adjuvant treatment planning, rather than nodal involvement, and a previous randomized trial comparing ALND versus no axillary surgery in clinically node-negative patients did not demonstrate an advantage in overall survival for patients submitted to ALND [6].

Prospective European studies are underway with the challenging assumption of verifying the utility of the SLNB itself, especially in specific subgroups of women with early breast cancer, that are less likely to metastasize regionally, as small, low-grade, biologically favorable tumors [43]. SOUND, INSEMA, and BOOG 2013-08 are studying the safety of omitting SLNB in BCS in the presence of clinically negative axillary nodes. In particular, the SOUND trial (Sentinel node $v$ Observation after axillary UltrasouND) is a prospective randomized multicenter study, designed by the European Institute of Oncology [46-48]. It was designed to compare SLNB versus observation (no axillary surgery) in patients with breast cancer $\leq 2 \mathrm{~cm}$ and a negative preoperative axillary ultrasound (US). Patients with a negative US, or with the single doubtful node negative on cytologic examination, are eligible for randomization to either $\mathrm{SNB} \pm$ axillary dissection or no surgical staging of the axilla (ie, no SNB nor axillary dissection). The primary endpoint is distant disease-free survival. Secondary endpoints are cumulative incidence of distant metastasis, of axillary disease, disease-free survival, and overall survival. Other endpoints are quality of life and assessment of influence of type of adjuvant treatment administered. The trial ended in June 2017, after the inclusion of 1,463 patients. A total of 1,416 patients were analyzed, 708 in each arm. In the SLNB arm, micrometastases were detected in $36(5.1 \%)$ patients and macrometastases in 61 (8.6\%) patients. Results on early disease-free survival are under evaluation. This study, together with ongoing INSEMA and BOOG 2013-08 trials, aims to evaluate whether the lack of pathologic lymph-node status information could be adequate in the adjuvant treatment decision-making process, bearing in mind the pressing necessity of improvements in diagnostic imaging given the low sensitivity of US [43].

\section{Looking toward the future}

Ongoing studies herald future research, involving breast cancer patients either with a conservative or radical (mastectomy) surgical plan, which could contribute to further scientific growth in axillary management, better defining the role of axillary treatment. The POSNOC trial (POsitive Sentinel NOde: adjuvant therapy alone vadjuvant therapy plus clearance or axillary radiotherapy) is a randomized controlled international trial of axillary treatment in women with early-stage breast cancer who have metastases in 1 or 2 sentinel nodes. It aims to assess whether or not adjuvant therapy alone is worse than adjuvant therapy plus axillary treatment, in terms of axillary recurrence within 5 years. The accrual target is 1,900 patients [49]. The SENOMAC trial, likewise, is recruiting patients with breast cancer that are candidates for either mastectomy or conservative surgery. It is a multicenter prospective randomized trial includes patients with clinically node-negative breast cancer presenting not more than 2 macrometastatic SLNs and is investigating the effect of omitting ALND in SLNB-positive patients. Randomization is between ALND completion and noncompletion. Its goal is to answer the clinically open questions related to the indications for ALND in T1-T3 tumors in $\mathrm{CN} 0$ patients. The primary endpoint is breast cancer-specific survival at 5 years. Secondary endpoints are locoregional recurrence, disease-free survival, and overall survival. Target accrual is 3,500. Its results will support the strengthening of the Z0011 trial conclusions, already applied in clinical practice in BCS for CT1-2N0 breast cancer patients [50].

With a goal of achieving ever greater regional control and reducing therapeutic morbidity, the ongoing ALLIANCE A011202 trial is studying the need of ALND in patients undergone to NAC who reached a nodal partial clinical response [51]. Trial design, with an estimated enrollment of 1,660 participants, aims to compare overall survival, locoregional recurrence and development of arm lymphedema after ALND versus axillary nodal irradiation among women who undergo SLNB and have residual nodal disease, ie, a metastasis greater than $0.2 \mathrm{~mm}$ in greatest dimension identified on intraoperative pathologic assessment [51]. January 2024 is the estimated primary completion date [51].

Regarding possible de-escalation of axillary surgery, in particular in relation to the risk of upstaging implied in axillary evaluation in DCIS, mention may also be made of the still-debated issue of the real value of SLNB in staging the axilla in microinvasive carcinoma (MIC) (Table 2bis). In the future, could we consider a potential omission of SLNB in selected cases of MIC? The incidence of axillary metastasis in sentinel nodes in MIC varies in studies from approximately $2 \%$ to $20 \%$ [52]. In a recent retrospective study from the European Institute of Oncology, that analyzed 257 women with microinvasive breast cancer who underwent SLNB, the reported incidence of axillary metastasis was $12.1 \%$, slightly higher than previously reported [53], and which falls within the range described in the published medical literature [52]. The low rate of macrometastases (1.9\%) with good overall survival and disease-free survival, suggests that SLNB may not be useful in MIC, owing to the small risk of lymph node metastasis and good prognosis. In this 


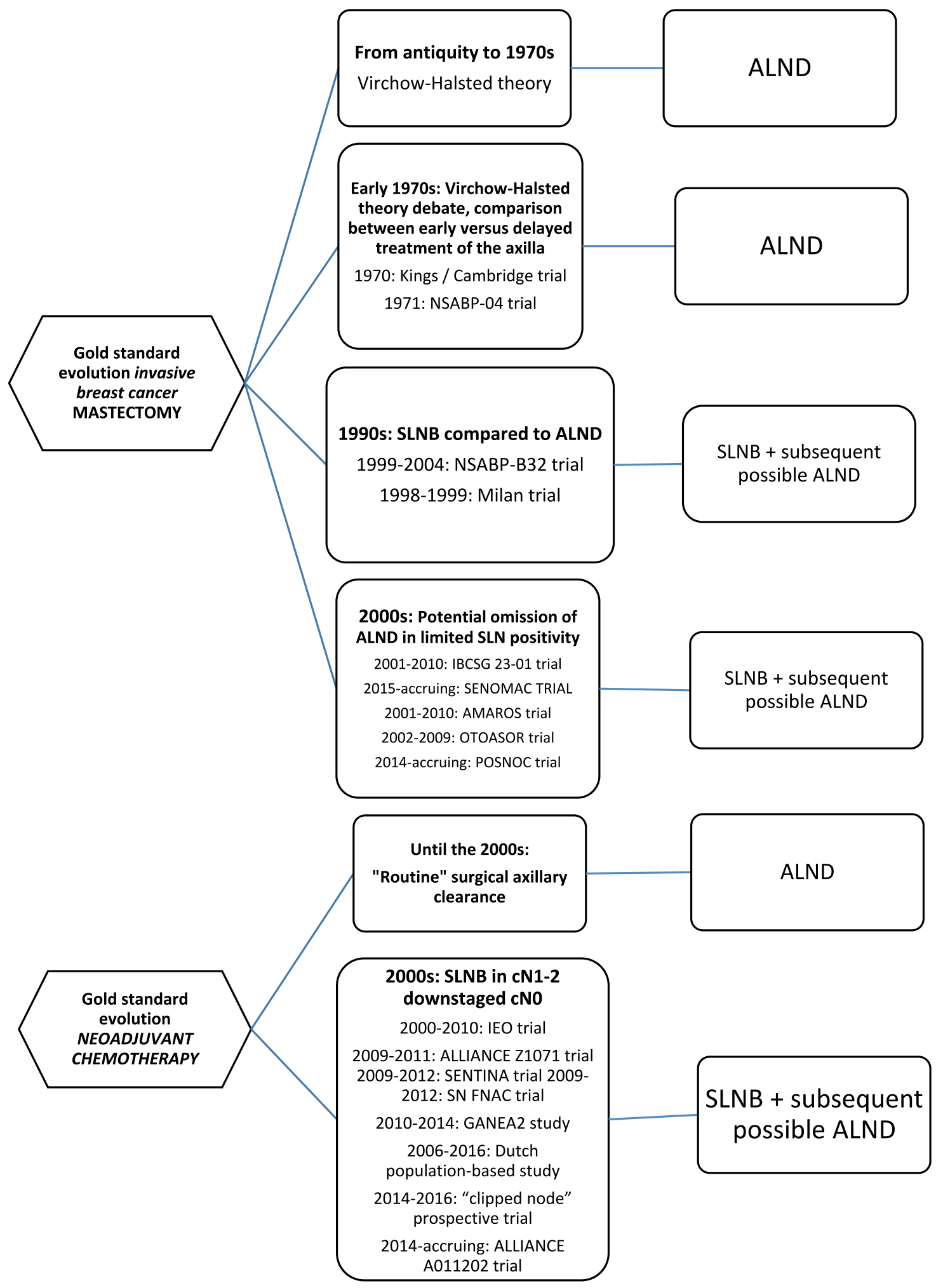

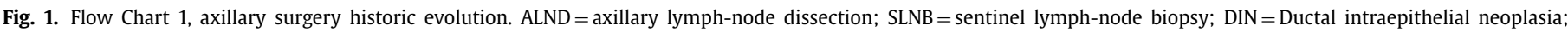
$\mathrm{BCS}=$ breast conserving surgery.

regard, also Phantana-angkool et al. recently reported a low SLN metastasis rate in patients with MIC preoperatively diagnosed on core biopsy and then confirmed at final pathology (2\%) [54]. Furthermore, a small rate of SLN metastases in microinvasive BC (2.9\%) was also described by Fan et al., who studied a wide cohort from a
National Cancer Database [55]. Indeed, these observations are supported by Level 1 evidence underlining that axillary dissection may be avoided in SLN-positive breast cancer patients undergoing BCS with radiotherapy when there is a low axillary metastatic burden (Z0011) [52]. 

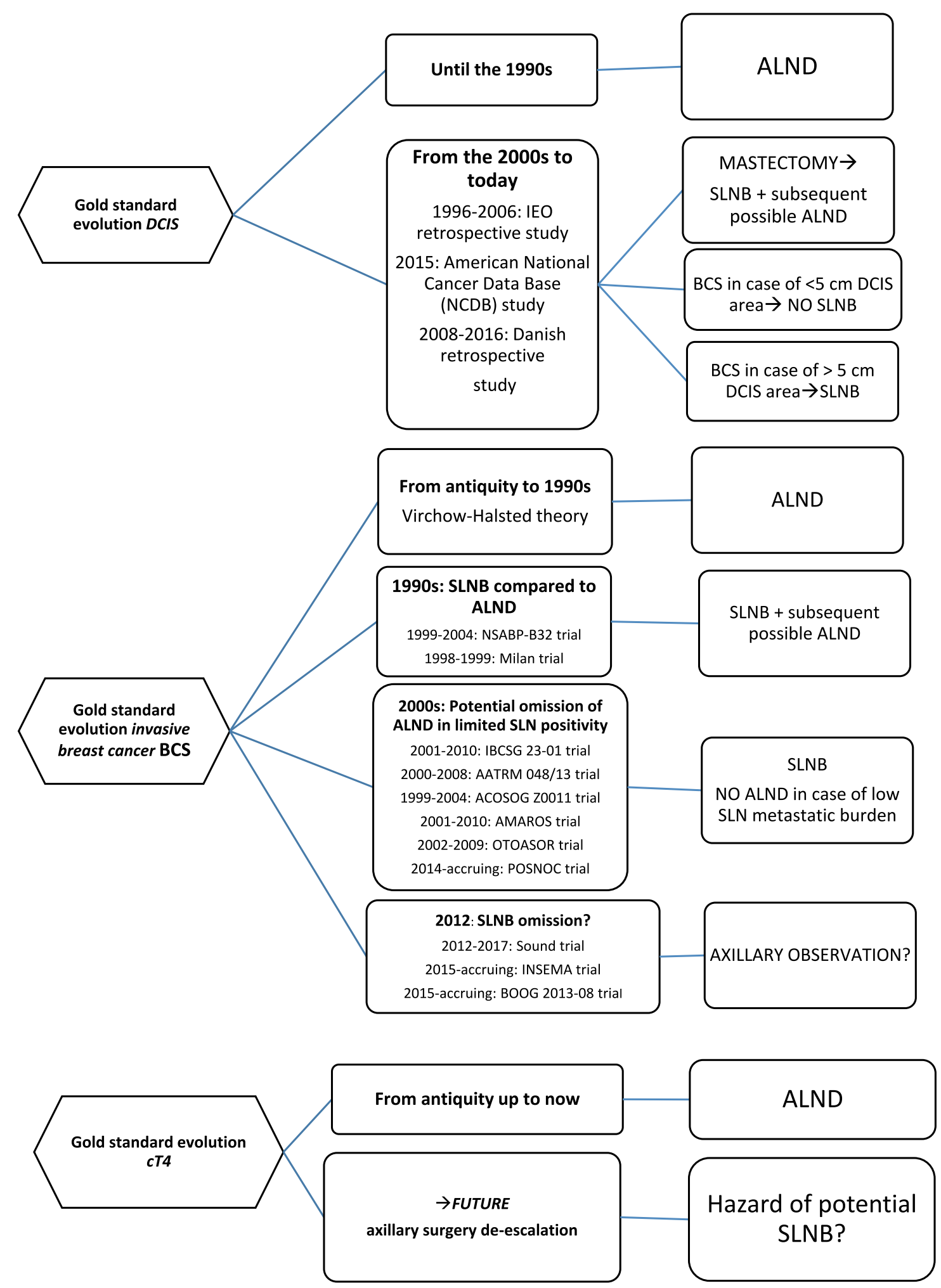

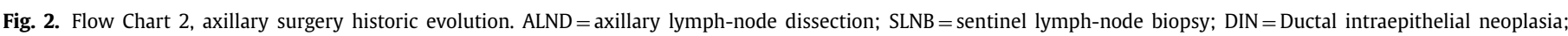
$\mathrm{BCS}=$ breast conserving surgery.

As outlined through this historical perspective, the common thread from the past that weaves its way through the present and stretches toward the future is the progressive tendency to reduce the extension of axillary lymph-node surgery in breast cancer management (Figs. 1 and 2). In clinical practice, the omission of ALND after SLNB with 1 or 2 positive SLNs following BCS is not harmful if radiotherapy and adequate adjuvant systemic treatments are planned. In tumors larger than $5 \mathrm{~cm}$, ALND may be omitted where radiotherapy is planned with regional nodal irradiation, including the axilla, as a component of localregional treatment [30]. 
Table 2bis

Ductal carcinoma in situ with microinvasion.

\begin{tabular}{|c|c|c|c|}
\hline Study & Design & Results & Comments \\
\hline $\begin{array}{l}\text { Retrospective } \\
\text { observational } \\
\text { study, } \\
\text { European Institute } \\
\text { of Oncology, Italy } \\
\text { Magnoni et al [52] } \\
\text { /Intra et al. [53] }\end{array}$ & $\begin{array}{l}310 \text { patients with DCISM } \rightarrow 257 \text { underwent } \\
\text { SLNB at the European Institute of } \\
\text { Oncology between } 1998-2010 \\
\text { Aim: better understanding of surgical and } \\
\text { prognostic implication of microinvasion } \\
\text { in BC }\end{array}$ & $\begin{array}{l}\text { - } 226 / 257(87.9 \%) \text { negative SLN; } \\
\text { - } 31 / 257(12.1 \%) \text { positive SLN: } 1.9 \% \\
\text { macrometastasis; } 5.4 \% \text { micrometastasis; } 4.7 \% \\
\text { ITCs. } \\
\text { - } 16 \text { positive SLNs } \rightarrow \text { ALND } \\
\text { - } 15 \text { positive SLNs } \rightarrow \text { no ALND } \\
\text { - The estimated } 10 \text {-year DFS rate was } 77.5 \% \text {, and } \\
\text { the estimated } 10 \text {-year; OS rate was } 94.8 \% \text {. } \\
\text { - } 1 \text { regional recurrence among patients with } \\
\text { positive SLNs who did not undergo ALND, } \\
\text { which was not significantly different from } \\
\text { recurrence in the group of patients who had } \\
\text { ALND after a positive SLNB. }\end{array}$ & $\begin{array}{l}\text { The findings of this study indicate } \\
\text { that SLNB may not be useful in } \\
\text { microinvasive DCIS owing to the } \\
\text { low risk of lymph node metastasis } \\
\text { and good prognosis }\end{array}$ \\
\hline $\begin{array}{l}\text { Retrospective study, } \\
\text { USA } \\
\text { Phantana-angkool } \\
\text { et al [54] }\end{array}$ & $\begin{array}{l}70 \text { patients diagnosed with DCISM on core } \\
\text { biopsy } \\
\text { Aims: -assess the upstage rate to invasive } \\
\text { cancer and axillary lymph node } \\
\text { metastasis in patients diagnosed with } \\
\text { DCISM } \\
\text { - whether predictive variables could be } \\
\text { identified that may help inform who } \\
\text { would most likely benefit from a surgical } \\
\text { axillary evaluation. }\end{array}$ & $\begin{array}{l}\text { - Upstaged rate }=30 \% \text { to measurable invasive } \\
\text { cancer }(>1 \mathrm{~mm}) \text {. } \\
\text { - } 49 \text { patients }(70 \%) \text { had a final diagnosis of } \\
\text { DCISM } \\
\text { - } 7 \% \text { rate of SLN metastasis when DCISM was } \\
\text { found on core biopsy. } \\
\text { - } 1 / 49 \text { patients }(2 \%) \text { with DCISM on final } \\
\text { pathology showed SLN metastases }\end{array}$ & $\begin{array}{l}\text { Findings of a positive SLNB were low } \\
\text { No predictive variables were } \\
\text { identified to inform whether the } \\
\text { routine practice of SLNB may be } \\
\text { omitted in some patients with } \\
\text { DCISM. }\end{array}$ \\
\hline $\begin{array}{l}\text { USA National } \\
\text { Database study } \\
\text { Fan et al. [55] }\end{array}$ & $\begin{array}{l}2609 \text { patients with DCISM who underwent } \\
\text { SLNB from } 2012 \text { to } 2015 \\
\text { Aim: identify risk factors for nodal } \\
\text { involvement in patients with DCISM, } \\
\text { which can help develop a selective } \\
\text { approach to SLNB in this patient } \\
\text { population }\end{array}$ & $\begin{array}{l}\text { - The rate of SLN metastases was only } 2.9 \% \\
\text { - Low/intermediate grade tumors were } \\
\text { associated with decreased SLN metastasis (OR } \\
0.50, \mathrm{CI} 0.28-0.92 \text { ) }\end{array}$ & $\begin{array}{l}\text { Positive SLN rate is very low } \\
\text { Tumor grade was identified as } \\
\text { influencing the risk of SLN } \\
\text { metastases }\end{array}$ \\
\hline
\end{tabular}

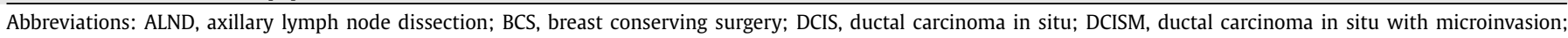
SLN, sentinel lymph node; SLNB, sentinel lymph node biopsy; disease-free survival; OS, overall survival.

This clinical approach should therefore be the standard of care for patients meeting ACOSOG Z0011 eligibility criteria, as endorsed and shared by the global panel of the 2019 Saint Gallen Consensus [30]. Indeed, long-term follow-up of the ACOSOG Z0011 trial confirms that ALND for 1-2 positive SLNs does not reduce local recurrence or improve OS [40]. On the other hand, the panel recommended completion ALND for women undergoing mastectomy with 1 or 2 positive SLNs, when no radiation or chest wall-only radiation was provided [30].

\section{Conclusions}

Scientific research will bear witness to several significant scenarios: a further possible de-escalation of ALND in mastectomy and a desirable improvement in the method of SLN identification and removal in cN1 becoming cN0 post-NAC patients, with special efforts concerning radioactive seed localization. Furthermore, the future might see an evaluation of the possible omission of ALND in the presence of post-NAC residual micrometastatic involvement in the SLN, as a result of extensive retrospective analysis studying outcomes of this specific cohort. Again, scientific research may lead to the promotion of axillary observation only, in selected cases of BCS. Last, forthcoming substantial studies might hazard a more challenging approach toward a reduction in axillary surgery in locally advanced invasive breast cancer, in particular, inflammatory breast cancer (IBC). To clearly define its clinical entity and optimize its treatment, as discussed and under current evaluation by the NCCN Panel [56], separate guidelines for IBC management and treatment could be suggested.

The goal, as ever, would be to ensure as optimal care as possible in a multimodal clinical management, consistently respecting women's quality of life.
Text Box 1

Take home points

- Morbidity is lower, and quality of life is higher in patients who undergo sentinel lymph-node biopsy (SLNB) compared to standard axillary lymph node dissection (ALND), without adverse effects on survival in long term follow-up results from large trials.

- SLNB is a minimally invasive procedure, and is the current best standard approach to the axilla in patients with clinically node-negative breast cancer. It is universally accepted as the turning point in axillary surgery.

- The current clinical practice recommendation is to perform SLNB only in selected patients with ductal carcinoma in situ (DCIS) in whom there is a substantial risk of an upgrade of the lesion at final pathology, as confirmed by the 2014 ASCO update recommendations.

- ALND is not justified for patients with micrometastatic sentinel-node involvement and this does not impact on survival, as deduced by wide clinical trials.

- ACOSOG Z0011 trial demonstrated that ALND does not confer an advantage in women with early breast cancer treated with breast conserving surgery (BCS), with no more than two involved SLNs, provided they received standard whole breast irradiation and adjuvant chemotherapy.

- ACOSOG Z0011 trial confirms that ALND for one to two positive SLNs does not reduce local recurrence or improve OS.

- Neoadjuvant chemotherapy (NAC) represents a valid tool in downstaging both breast and axillary disease. The 2019 St. Gallen Conference Panel considered SLNB appropriate in the clinically negative axilla before neoadjuvant treatments, and strongly recommended it. 
- For patients with clinically involved axillary lymph nodes, downstaged after neoadjuvant treatment, the performance of SLNB after NAC remains controversial.

- Results from several prospective and retrospective trials suggested that SLNB is acceptable in cN1/2 patients downstaged to $\mathrm{cNO}$ after neoadjuvant therapy.

- The 2019 St. Gallen consensus conference believed SLNB, as opposed to ALND, to be adequate in $\mathrm{cN} 1 / 2$ patients down-staged to cNO after neoadjuvant therapy, if at least three or more negative sentinel nodes were detected and examined, underlining the persistence of high FNR unless three or more SNs are examined, recommending that patients with a clinically positive axilla or with macrometastases identified in SLN after NAC undergo ALND.

- Prospective European studies (SOUND, INSEMA and BOOG 2013-08) are underway with the challenging assumption of verifying the utility of the SLNB itself, especially in specific subgroups of women with early breast cancer, studying the safety of omitting SLNB in BCS in the presence of clinically negative axillary nodes.

- Ongoing studies herald future research, involving breast cancer patients either with a conservative or radical (mastectomy) surgical plan, which could contribute to further scientific growth in axillary management, better defining the role of axillary treatment: future is waiting for results from POSNOC, SENOMAC and ALLIANCE A011202 trials.

- The 2019 St. Gallen Conference Panel recommended completion ALND for women undergoing mastectomy with one or two positive SLNs, when no radiation or chest wallonly radiation was provided.

- In the future, could we consider a potential omission of SLNB in selected cases of microinvasive carcinoma?

- In the future scientific research will bear witness to several significant scenarios:

- a further possible de-escalation of ALND in mastectomy

- a desirable improvement in the method of SLN identification and removal in cN1 becoming cN0 post-NAC patients

- a possible omission of ALND in the presence of postNAC residual micrometastatic involvement in the SLN

- the promotion of axillary observation only in selected cases of BCS

- a more challenging approach towards a reduction in axillary surgery in locally advanced invasive breast cancer, in particular, inflammatory breast cancer

\section{Conflicts of interest}

The authors declare that they have no conflict of interest.

\section{Acknowledgment}

We acknowledge William Russell-Edu for his support in editing the draft of this manuscript and Maria Grazia Villardita for her editorial assistance.

This work was partially supported by the Italian Ministry of Health with Ricerca Corrente and $5 \times 1000$ funds.

\section{References}

[1] Jatoi I, Benson JR. Surgical management of the axilla in early breast cancer. Curr Probl Surg 2018;55(2):47-65.

[2] Le Dran HF. Memoires avec un precis de plusieurs observations sur le cancer. Mem Acad R Chir 1757;3:1-54.

[3] Virchow R. Cellular pathology. Philadelphia, PA: Lippincott; 1863.

[4] Halsted WSI. The results of operations for the cure of cancer of the breast performed at the Johns Hopkins Hospital from June, 1889, to January, 1894. Ann Surg 1894;20(5):497-555.

[5] Halsted WSI. The results of radical operations for the cure of carcinoma of the breast. Ann Surg 1907;46(1):1-19.
[6] Bromham N, Schmidt-Hansen M, Astin M, Hasler E, Reed MW. Axillary treatment for operable primary breast cancer. Cochrane Database Syst Rev 2017:1(1):CD004561.

[7] Amin MB, Edge SB. AJCC cancer staging manual. New York: Springer; 2017

[8] Corso G, Galimbertin V, Veronesi P. De-escalation treatment of axilla in breast cancer. Clin Transl Oncol 2020;22:445-6.

[9] Veronesi U, Paganelli G, Viale G, et al. A randomized comparison of sentinel-node biopsy with routine axillary dissection in breast cancer. N Engl J Med 2003;349(6):546-53.

[10] Lyman GH, Giuliano AE, Sommerfield MR, et al. American Society of Clinical Oncology guideline recommendations for sentinel lymph node biopsy in early-stage breast cancer. J Clin Oncol 2005;23:7703-20.

[11] Krag DN, Anderson SJ, Julian TB, et al. Sentinel-lymph-node resection compared with conventional axillary-lymph-node dissection in clinically node-negative patients with breast cancer: overall survival findings from the NSABPB-32 randomised phase 3 trial. Lancet Oncol 2010;11(10):927-33.

[12] Veronesi U, Viale G, Paganelli G, et al. Sentinel lymph-node biopsy in breast cancer: ten-year results of a randomized controlled study. Ann Surg 2010:251(4):595-600

[13] Giuliano AE, Han SH. Local and regional control in breast cancer: role of sentinel node biopsy. Adv Surg 2011;45:101-16.

[14] Galimberti V, Monti S, Mastropasqua MG. DCIS and LCIS are confusing and outdated terms. They should be abandoned in favor of ductal intraepithelial neoplasia (DIN) and lobular intraepithelial neoplasia (LIN). Breast 2013;22:431-5.

[15] Farante G, Galimberti V, Zurrida S, et al. No more axillary dissection in patients with ductal intraepithelial neoplasia (DIN). Eur J Cancer 2010;46(3):476-8.

[16] Lyman GH, Somerfield MR, Bosserman LD, Perkins CL, Weaver DL, Giuliano AE. Sentinel lymph node biopsy for patients with early-stage breast cancer: American Society of Clinical Oncology clinical practice guideline update. J Clin Oncol 2017;35(5):561-4.

[17] Intra $M$, Rotmensz $N$, Veronesi $P$, et al. Sentinel node biopsy is not a standard procedure in ductal carcinoma in situ of the breast: the experience of the European Institute of Oncology on 854 patients in 10 years. Ann Surg 2008;247(2):315-19.

[18] Lyman GH, Temin S, Edge SB, et al. American Society of Clinical Oncology Clinical Practice. Sentinel lymph node biopsy for patients with early-stage breas cancer: American Society of Clinical Oncology clinical practice guideline update. J Clin Oncol 2014;32:1365-83.

[19] James TA, Pals B, McCabe R, et al. Evaluating the role of sentinel lymph node biopsy in patients with DCIS treated with breast conserving surgery. Am J Surg 2020;220:654-9.

[20] Munck F, Clausen EW, Balslev E. Multicentre study of the risk of invasive cancer and use of sentinel node biopsy in women with a preoperative diagnosis of ductal carcinoma in situ. Br J Surg 2020;107:96-102.

[21] Galimberti V, Cole BF, Zurrida S. Axillary dissection versus no axillary dissection in patients with sentinel-node micrometastases (IBCSG 23-01): a phase 3 randomised controlled trial. Lancet Oncol 2013;14(4):297-305.

[22] Galimberti V, Cole BF, Viale G, et al. Axillary dissection versus no axillary dissection in patients with breast cancer and sentinel-node micrometastases (IBCSG 23-01): 10-year follow-up of a randomised, controlled phase 3 trial. Lancet Oncol 2018:19(10):1385-93.

[23] Solá M, Alberro JA, Fraile M, et al. Complete axillary lymph node dissection versus clinical follow-up in breast cancer patients with sentinel node micrometastasis: final results from the multicenter clinical trial AATRM 048/13/2000. Ann Surg Oncol 2013;20(1):120-7

[24] Giuliano AE, Ballman KV, McCall L, et al. Effect of axillary dissection vs no axillary dissection on 10-year overall survival among women with invasive breast cancer and sentinel node metastasis: the ACOSOG Z0011 (Alliance) randomized clinical trial. JAMA 2017;318:918-26.

[25] Veronesi P, Corso G. Standard and controversies in sentinel node in breast cancer patients. Breast 2019(48S1):S53-6.

[26] Donker M, van Tienhoven G, Straver ME, et al. Radiotherapy or surgery of the axilla after a positive sentinel node in breast cancer (EORTC 10981-22023 AMAROS): a randomised, multicentre, open-label, phase 3 non-inferiority trial. Lancet Oncol 2014:15:1303-10.

[27] Morrow M. Management of the node-positive axilla in breast cancer in 2017: selecting the right option. JAMA Oncol 2018;4:250-1.

[28] Sávolt Á, Péley G, Polgár C, et al. Eight-year follow up result of the OTOASOR trial: The Optimal Treatment Of the Axilla - Surgery Or Radiotherapy after positive sentinel lymph node biopsy in early-stage breast cancer: a randomized, single centre, phase III, non-inferiority trial. Eur J Surg Oncol 2017;43(4):672-9.

[29] Morigi C, Peradze N, Galimberti V, et al. Feasibility and surgical impact of Z0011 trial criteria in a single-Institution practice. Breast J 2020;26(7):13306. doi:10.1111/tbj.13851.

[30] Burstein HJ, Curigliano G, Loibl S, et al. Estimating the benefits of therapy for early-stage breast cancer: the St. Gallen International Consensus Guidelines for the primary therapy of early breast cancer 2019. Ann Oncol 2019;30(10):1541-57.

[31] Boughey JC, Ballman KV, Le-Petross HT, et al. Identification and resection of clipped node decreases the false-negative rate of sentinel lymph node surgery in patients presenting with node-positive breast cancer (T0-T4, N1-N2) who receive neoadjuvant chemotherapy: results from ACOSOG Z1071 (Alliance). Ann Surg 2016;263:802-7.

[32] Lim GH, Teo SY, Gudi M, et al. Initial results of a novel technique of clipped node localization in breast cancer patients postneoadjuvant chemotherapy: 
Skin Mark clipped Axillary nodes Removal Technique (SMART trial). Cancer Med 2020;9:1978-85.

[33] Yan M, Abdi MA, Falkson CB. Axillary management in breast cancer patients: a comprehensive review of the key trials. Clin Breast Cancer 2018; 18:1251-9.

[34] Tee SR, Devane LA, Evoy D, et al. Meta-analysis of sentinel lymph node biopsy after neoadjuvant chemotherapy in patients with initial biopsy-proven nodepositive breast cancer. Br J Surg 2018;105:1541-52.

[35] Galimberti V, Ribeiro Fontana SK, Maisonneuve P, et al. Sentinel node biopsy after neoadjuvant treatment in breast cancer: five-year follow-up of patients with clinically node-negative or node-positive disease before treatment. Eur J Surg Oncol 2016;42:361-8.

[36] Corso G, Grana CM, Gilardi L, et al. Feasibility of lymphoscintigraphy for sentinel node identification after neo-adjuvant therapy. Ann Ital Chir 2017;88:201-5.

[37] Classe JM, Loaec C, Gimbergues P, et al. Sentinel lymph node biopsy without axillary lymphadenectomy after neoadjuvant chemotherapy is accurate and safe for selected patients: the GANEA 2 study. Breast Cancer Res Treat 2018; 173:343-52.

[38] Simons JM, Koppert LB, Luiten EJT, et al. De-escalation of axillary surgery in breast cancer patients treated in the neoadjuvant setting: a Dutch population-based study. Breast Cancer Res Treat 2020;180:725-33.

[39] Caudle AS, Yang WT, Krishnamurthy S, et al. Improved axillary evaluation following neoadjuvant therapy for patients with node-positive breast cancer using selective evaluation of clipped nodes: implementation of targeted axillary dissection. J Clin Oncol 2016;34:1072-8.

[40] Siso C, de Torres J, Esgueva-Colmenarejo A, et al. Intraoperative ultrasound-guided excision of axillary clip in patients with node-positive breast cancer treated with neoadjuvant therapy (ILINA trial). Ann Surg Oncol 2018;25:784-91.

[41] Cabıoğlu N, Karanlık H, Kangal D, et al. Improved false-negative rates with intraoperative identification of clipped nodes in patients undergoing sentinel lymph node biopsy after neoadjuvant chemotherapy. Ann Surg Oncol 2018:25:3030-6.

[42] Magnoni F, Accardo G, Rossi E, et al. Anatomy is not enough: the crucial role of biology and genetics in AJCC eighth edition of the TNM classification for breast cancer. Ann Transl Med 2019;7(1):S34.

[43] Reimer T, Engel J, Schmidt M, et al. Is axillary sentinel lymph node biopsy required in patients who undergo primary breast surgery? Breast Care (Basel) 2018;13(5):324-30.

[44] Dengel LT, Van Zee KJ, King TA, et al. Axillary dissection can be avoided in the majority of clinically node-negative patients undergoing breast conserving therapy. Ann Surg Oncol 2014;21:22-7.
[45] Ibrahim-Zada I, Grant CS, Glazebrook KN, Boughey JC. Preoperative axillary ultrasound in breast cancer: safely avoiding frozen section of sentinel lymph nodes in breast-conserving surgery. J Am Coll Surg 2013;217:7-15.

[46] https://clinicaltrials.gov/ct2/show/NCT02167490. Sentinel Node Vs Observation After Axillary Ultra-souND (SOUND). (Accessed June 4, 2020).

[47] Gentilini O, Botteri E, Dadda P, et al. Physical function of the upper limb after breast cancer surgery. Results from the SOUND (Sentinel node vs. Observation after axillary Ultra-souND) trial. Eur J Surg Oncol 2016;42:685-9.

[48] Gentilini O, Veronesi U. Abandoning sentinel lymph node biopsy in early breast cancer? A new trial in progress at the European Institute of Oncology of Milan (SOUND: Sentinel node vs Observation after axillary UltraSouND). Breast 2012;21:678-81.

[49] Goya A. POsitive Sentinel NOde-adjuvant therapy alone versus adjuvant therapy plus Clearance or axillary radiotherapy: a randomized controlled trial of axillary treatment in women with early stage breast cancer who have metastases in one or two sentinel nodes. Available at: http://www.thelancet.com/ doi/story/10.1016/html.2014.12.08.1563; Accessed June 6, 2020.

[50] De Boniface J, Frisell J, Andersson Y, et al. Survival and axillary recurrence following sentinel node-positive breast cancer without completion axillary lymph node dissection: the randomized controlled SENOMAC trial. BMC Cancer 2017; 17:379

[51] Alliance for Clinical Trials in Oncology. Bethesda (MD): National Library of Medicine (US); 2013. Comparison of Axillary Lymph Node Dissection With Axillary Radiation for Patients With Node-Positive Breast Cancer Treated With Chemotherapy (ALLIANCE A011202). ClinicalTrials.gov [Internet][cited 2020 Jul 29] Available from: https://clinicaltrials.gov/ct2/show/ NCT01901094 NLM Identifier: NCT01901094.

[52] Magnoni F, Massari G, Santomauro G, et al. Sentinel lymph node biopsy in microinvasive ductal carcinoma in situ. Br J Surg 2019;106:375-83.

[53] Intra M, Zurrida S, Maffini F, et al. Sentinel lymph node metastasis in microinvasive breast cancer. Ann Surg Oncol 2003;10(10):1160-5.

[54] Phantana-angkool A, Voci AE, Warren YE, et al. Ductal carcinoma in situ with microinvasion on core biopsy: evaluating tumor upstaging rate, lymph node metastasis rate, and associated predictive variables. Ann Surg Oncol 2019;26:3874-82.

[55] Fan B, Pardo JA, Serres S, et al. Role of sentinel lymph node biopsy in microinvasive breast cancer. Ann Surg Oncol 2020;27(11):4468-73.

[56] Network NCC. Breast Cancer (Version 3.2020). (C2020 National Comprehensive Guidelines Network $\circledast N C C N \circledast$. Accessed June 6, 2020. 